\section{Absence of contagious yawning in children with autism spectrum disorder}

\author{
Atsushi Senju ${ }^{1, *}$, Makiko Maeda ${ }^{2}$, \\ Yukiko Kikuchi ${ }^{2}$, Toshikazu Hasegawa ${ }^{2}$, \\ Yoshikuni Tojo ${ }^{3}$ and Hiroo Osanai ${ }^{4}$ \\ ${ }^{1}$ Centre for Brain and Cognitive Development, Birkbeck College, \\ University of London, Malet Street, London WC1E 7HX, UK \\ ${ }^{2}$ Department of Cognitive and Behavioral Science, University of Tokyo, \\ 3-8-1 Komaba, Meguroku, Tokyo 153-8902, Japan \\ ${ }^{3}$ Ibaraki University, Faculty of Education, 2-1-1 Bunkyo, Mito, \\ Ibaraki 310-8512, Fapan \\ ${ }^{4}$ Musashino Higashi Gakuen, 2-1-0 Midoricho, Musashino, \\ Tokyo 180-0012, Japan \\ *Author for correspondence (a.senju@bbk.ac.uk).
}

This study is the first to report the disturbance of contagious yawning in individuals with autism spectrum disorder (ASD). Twenty-four children with ASD as well as 25 age-matched typically developing (TD) children observed video clips of either yawning or control mouth movements. Yawning video clips elicited more yawns in TD children than in children with ASD, but the frequency of yawns did not differ between groups when they observed control video clips. Moreover, TD children yawned more during or after the yawn video clips than the control video clips, but the type of video clips did not affect the amount of yawning in children with ASD. Current results suggest that contagious yawning is impaired in ASD, which may relate to their impairment in empathy. It supports the claim that contagious yawning is based on the capacity for empathy.

Keywords: yawning; contagious yawning; autism spectrum disorder; empathy; neuropathology

\section{INTRODUCTION}

Contagious yawning (i.e. yawning triggered by perceiving others' yawning) is a well-documented phenomenon (e.g. Lehmann 1979; Provine 1986, 1989; Anderson \& Meno 2003; Platek et al. 2003), but surprisingly little is known about the mechanisms underlying it. Contagious yawning is reported in humans and in only a few other primates such as chimpanzee (Pan troglodytes; Anderson et al. 2004) and possibly in stumptail macaques (Macaca arctoides; Paukner \& Anderson 2006), even though spontaneous yawning is widespread among vertebrate species (Baenninger 1987). Some authors argue that contagious yawning is a response to an innate releasing mechanism (Provine 1986, 1989), whereas others claim that it is based on the capacity for empathy (Lehmann 1979; Preston \& de Waal 2002; Platek et al. 2003).

Although various neurological or psychiatric disorders are known to cause abnormal patterns of

Electronic supplementary material is available at http://dx.doi.org/ 10.1098/rsbl.2007.0337 or via http:/www.journals.royalsoc.ac.uk. spontaneous yawning (Daquin et al. 2001), no study has tested whether a neuropathology causes contagious yawning to be impaired. We predicted that individuals with autism spectrum disorder (ASD) would have impaired contagious yawning. ASD is a pervasive developmental disorder, which severely affects social and communicative development (America Psychiatric Association 1994), including empathy (Baron-Cohen et al. 2005; Blair 2005). If contagious yawning is related to the capacity for empathy, then it is possible that individuals with ASD, who have impairment in empathy, show the disturbances in contagious yawning. In addition, a recent neuroimaging study (Schürmann et al. 2005) reported that observation of others' yawning and susceptibility to yawn in response are related to the activity of the superior temporal sulcus and periamygdalar regions. Since structural abnormalities of these regions are reported in ASD (Schumann et al. 2004; Zilbovicius et al. 2006), they should show disturbances in contagious yawning. However, to date, there are no empirical studies that systematically investigated contagious yawning in ASD.

The aim of this study is to assess the contagious yawning of children with ASD, using video clips of yawning as stimuli. Children at or over the age of 7 years participated in the study because Anderson \& Meno (2003) reported that children older than 4 years reliably show contagious yawning. In addition to the yawning video clips, control video clips of mouth-opening action were also presented to the participants. If the children with ASD have disturbances specific to contagious yawning, observing yawning videos should elicit less yawning in children with ASD than in typically developing (TD) children, while the amount of yawning should not differ between groups during or after the observation of control videos.

\section{MATERIAL AND METHODS}

\section{(a) Participants}

Data from 24 children with ASD (4 females) and 25 age-matched TD children (11 females) were included in the analyses (table 1). The children with ASD have been diagnosed with an autistic disorder by a clinician according to DSM-IV (American Psychiatric Association 1994). In addition, parents of all the participants completed a Japanese version of the Autism Screening Questionnaire (ASQ-J; Berument et al. 1999; Dairoku et al. 2004), and only the children who scored above the cut-off point (13) were included in the analysis. Four additional children did not meet this criterion and were excluded from the analyses. Note that all TD children scored well below the cut-off in ASQ-J. An abbreviated version of Japanese WISC-III (Japanese WISC-III Publication Committee 1998) was also administrated to measure IQ. Informed consent was obtained from both the children and their parents. The study was approved by the University of Tokyo Research Ethics Committee.

\section{(b) Stimuli and procedure}

The stimuli consisted of six video clips of yawning faces ( $7 \mathrm{~s}$ each) taken from different adult models and six control video clips (mouth opening, $7 \mathrm{~s}$ each) of the same six models. All the models were unfamiliar to the participants. Stimuli were presented in a pseudorandom order, with 1 min inter-stimulus interval between stimuli. During the interval, a silent cartoon animation was presented to keep the participants' attention towards the display. Stimulus sequences were presented on the 12 in. LCD monitor of a laptop computer, and the face that appeared measured $10 \times 15 \mathrm{~cm}$ on the monitor.

All the participants viewed the movies in a soundproofed room and were asked to count the number of female faces that appeared during the movie. All the children correctly counted the faces, which ensured that they attended to the display. The faces of the 
Table 1. Participants' age, verbal, performance and full IQ and score on the Japanese version of Autism Screening Questionnaire (ASQ-J). (ASD, children with autism spectrum disorders; TD, typically developing children; IQ, intelligence quotient.)

\begin{tabular}{|c|c|c|c|c|}
\hline & \multicolumn{4}{|l|}{ group } \\
\hline & \multicolumn{2}{|c|}{$\operatorname{ASD}(n=24)$} & \multicolumn{2}{|c|}{$\mathrm{TD}(n=25)$} \\
\hline & $M$ & s.d. & $M$ & s.d. \\
\hline age (years) & 11.6 & 2.3 & 11.0 & 2.2 \\
\hline range & $7.0-15.9$ & & $8.0-14.9$ & \\
\hline verbal IQ & 83.0 & 30.1 & 111.5 & 17.0 \\
\hline range & $46-136$ & & $88-154$ & \\
\hline performance IQ & 81.3 & 23.3 & 100.7 & 17.3 \\
\hline range & $46-124$ & & $70-130$ & \\
\hline full IQ & 82.1 & 25.7 & 106.1 & 14.9 \\
\hline range & $46-127$ & & $85-142$ & \\
\hline ASQ-J & 23.3 & 5.2 & 2.3 & 2.5 \\
\hline range & $16-33$ & & $0-9$ & \\
\hline
\end{tabular}

participants were recorded using a custom-built hidden video recorder. The videos were coded off-line. The coder was blind to the stimulus the children were watching. After the coding, the number of yawns during or after the observation of each stimulus (and before the onset of the following stimulus) was calculated and analysed. Two independent coders coded the entire dataset and inter-rater reliability was high $(\kappa=0.83)$.

\section{RESULTS}

The yawning videos elicited more yawning in TD children than in children with ASD (Mann-Whitney test: $z=-2.80, p=0.01$ ), but the control movies showed no difference between groups in the number of yawns (Mann-Whitney test: $z=-1.28, p>0.1$; figure 1). Within-group analyses also revealed that in TD children, yawning videos elicited more yawning than control videos (Wilcoxon signed-rank test: $z=-2.07, p=0.038$, one-tailed). However, children with ASD did not show any difference between yawning and control videos (Wilcoxon signed-rank test: $z=-0.43, p>0.1)$.

In both children with ASD and TD children, the number of yawns did not correlate with age, IQ or scores of ASQ-J (Spearman: all $\rho<0.31, p>0.1$ ). The effect of gender on the frequency of yawning in the yawn and control conditions was examined both in ASD and TD group, and no significant effect of gender was found. In addition, group differences in the yawning condition remained significant when only male participants were compared (Mann-Whitney test: $z=-2.01, p=0.044$, one-tailed). Again, the control condition did not show a significant group effect in this subgroup (Mann-Whitney test: $z=-1.69, p>0.1$ ).

To further examine the effect of IQ, an additional group comparison was conducted with the IQ-matched subgroups of $16 \mathrm{TD}$ children (7 females) and 16 children with ASD ( 3 females; see table in the electronic supplementary material). Results confirmed the main findings: TD children elicited more yawns than children with ASD in the yawning condition (Mann-Whitney test: $z=-2.39, p=0.034$ ), but not in the control condition (Mann-Whitney test: $z=-0.79$, $p>0.1)$.

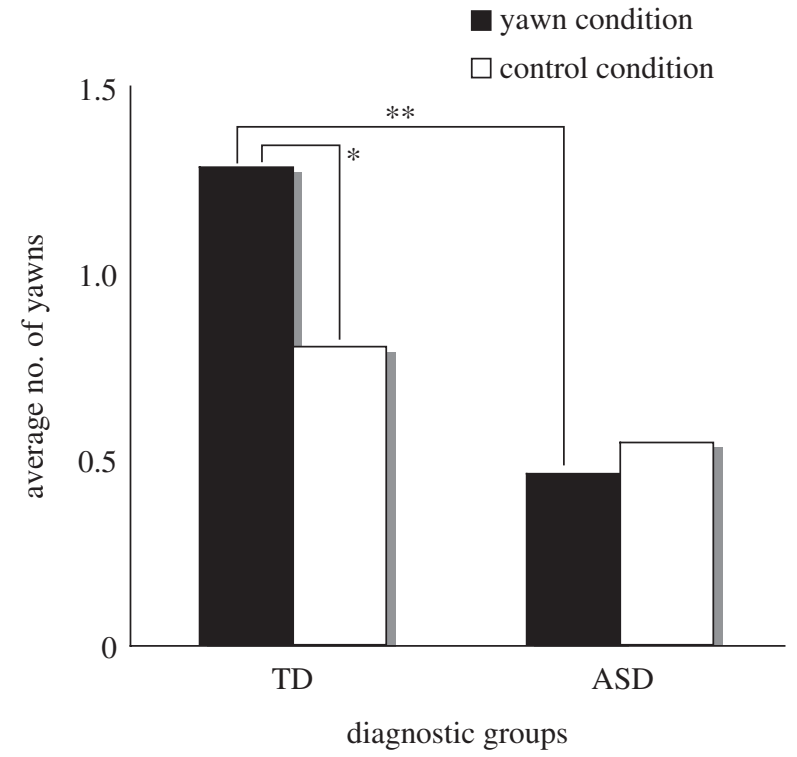

Figure 1. Average frequency of yawns of participants during or after the observation of yawn and control conditions. TD, typically developing children; ASD, children with autism spectrum disorder; ${ }^{* *} p<0.01 ;{ }^{*} p<0.05$.

Note that Bonferroni corrections were applied to all multiple comparisons.

\section{DISCUSSION}

This study is the first to demonstrate an impairment in contagious yawning in children with ASD. During or after the observation of a video of a yawning adult, children with ASD yawned significantly less than TD children. This cannot be attributed to the overall differences in the frequency of spontaneous yawning because the amount of yawning did not differ between groups during or after they observed mouth-opening, control, videos. In addition, the results of typically developing TD children replicated a previous study (Anderson \& Meno 2003) that TD children yawn more during the observation of others' yawning than other mouth movements. However, others' yawning did not modulate the frequency of yawns in children with ASD.

To the best of the authors' knowledge, this is the first report to demonstrate that a neurodevelopmental disorder can lead to an impairment specific to contagious yawning, and not spontaneous yawning. Since atypical development of empathy is reported in ASD (Baron-Cohen et al. 2005; Blair 2005), current results support the claim that contagious yawning and the capacity of empathy share common neural and cognitive mechanisms (Lehmann 1979; Preston \& de Waal 2002; Platek et al. 2003). To further examine the involvement of empathy in contagious yawning, it will be important to investigate whether contagious yawning is impaired in other 'empathy disorders' (Preston \& de Waal 2002) such as psychopathy, prefrontal damage or front-temporal dementia.

One might argue that impaired contagious yawning in ASD relates to the dysfunction of the mirrorneuron system (MNS), as is their imitative impairment (Ramachandran \& Oberman 2006). However, this argument needs to be treated with caution. For 
example, Schürmann et al. (2005) did not find selective activation of Broca's area, the essential component of MNS (Rizzolatti \& Craighero 2004), during observation of others' yawning. It suggests 'the non-imitative nature of the yawn contagion that can occur without detailed action understanding' (Schürmann et al. 2005, p. 1264).

Individuals with ASD are known to fixate more to the mouth than to the eyes when watching dynamic facial stimuli (e.g. Klin et al. 2002). Since the perception of the eye region of yawning people is a potent stimulus for yawn contagion (Provine 1989), it is possible that less fixation to the eyes of yawning stimuli may impede the contagious yawning in children with ASD. Further studies will be beneficial to examine whether the atypical pattern of face fixation contributes to the impairment in contagious yawning.

As mentioned above, little is known about the mechanism and development, as well as the function, of contagious yawning. Further studies are required to investigate the relation between contagious yawning and other symptoms of ASD, such as empathy, imitation and/or face fixation. In addition, further studies will be beneficial to explore the developmental course of contagious yawning in ASD. Although we did not find any effect of age or IQ in the current age group, it is still possible that chronological or mental age would affect the manifestation of contagious yawning in other age groups. These would be fruitful lines of research, not only in order to clarify the mechanism and function of yawning, but also to better understand the nature of social and communicative impairment in ASD.

This study was approved by the University of Tokyo Research Ethics Committee.

We thank all the children and their parents for participation, and Gergely Csibra, Mayada Elsabbagh and Sarah Fox for their help in preparing earlier versions of the manuscript. This study was supported by the Japan Society for the Promotion of Science, twenty-first century COE Program J05, 'Center for Evolutionary Cognitive Sciences at the University of Tokyo', and A.S. was supported by an ESRC/MRC Joint Postdoctoral Fellowship.

American Psychiatric Association 1994. Diagnostic and statistical manual of mental disorders, 4th edn. Washington, DC: American Psychiatric Association.

Anderson, J. R. \& Meno, P. 2003 Psychological influences on yawning in children. Curr. Psychol. Lett. Behav. Brain Cogn. 11. (http://cpl.revues.org/document390.html)

Anderson, J. R., Myowa-Yamakoshi, M. \& Matsuzawa, T. 2004 Contagious yawning in chimpanzees. Proc. R. Soc. B 271(Suppl. 6), S468-S470. (doi:10.1098/rsbl.2004.0224)

Baenninger, R. 1987 Some comparative aspects of yawning in Betta splendens, Homo sapiens, Panthera leo, and Papio sphinx. F. Comp. Psychol. 101, 349-354. (doi:10.1037/ 0735-7036.101.4.349)
Baron-Cohen, S., Knickmeyer, R. C. \& Belmonte, M. K. 2005 Sex differences in the brain: implications for explaining autism. Science 310, 819-823. (doi:10.1126/ science.1115455)

Berument, S. K., Rutter, M., Lord, C., Pickles, A. \& Bailey, A. 1999 Autism screening questionnaire: diagnostic validity. Br. F. Psychiatry 175, 444-451.

Blair, R. J. 2005 Responding to the emotions of others: dissociating forms of empathy through the study of typical and psychiatric populations. Conscious. Cogn. 14, 698-718. (doi:10.1016/j.concog.2005.06.004)

Dairoku, H., Senju, A., Hayashi, E., Tojo, Y. \& Ichikawa, H. 2004 Development of Japanese version of autism screening questionnaire. Kokuritsu Tokushu Kyoiku Kenkyusho Ippan Kenkyu Houkokusho 7, 19-34.

Daquin, G., Micallef, J. \& Blin, O. 2001 Yawning. Sleep Med. Rev. 5, 299-312. (doi:10.1053/smrv.2001.0175)

Japanese WISC-III Publication Committee 1998 Nihonban WISC-III chinou kensahou, 3rd edn. Tokyo, Japan: Nihon Bunka Kagakusha. [Japanese Wechsler Intelligence Scale for Children.]

Klin, A., Jones, W., Schultz, R., Volkmar, F. \& Cohen, D. 2002 Visual fixation patterns during viewing of naturalistic social situations as predictors of social competence in individuals with autism. Arch. Gen. Psychiatry 59, 809-816. (doi:10.1001/archpsyc.59.9.809)

Lehmann, H. E. 1979 Yawning: a homeostatic reflex and its psychological significance. Bull. Meninger Clin. 43, 123-136.

Paukner, A. \& Anderson, J. R. 2006 Video-induced yawning in stumptail macaques (Macaca arctoides). Biol. Lett. 2, 36-38. (doi:10.1098/rsbl.2005.0411)

Platek, S. M., Critton, S. R., Myers, T. E. \& Gallup, G. G. 2003 The role of self-awareness and mental state attribution. Brain Res. Cogn. Brain Res. 17, 223-227. (doi:10. 1016/S0926-6410(03)00109-5)

Preston, S. D. \& de Waal, F. B. 2002 Empathy: its ultimate and proximate bases. Behav. Brain Sci. 25, 1-20. (doi:10.1017/S0140525X02000018)

Provine, R. R. 1986 Yawning as a stereotyped action pattern and releasing stimulus. Ethology 72, 448-455.

Provine, R. R. 1989 Yawning and simulation science. Simulation 53, 193-194.

Ramachandran, V. S. \& Oberman, L. M. 2006 Broken mirrors: a theory of autism. Sci. Am. 295, 62-69.

Rizzolatti, G. \& Craighero, L. 2004 The mirror-neuron system. Annu. Rev. Neurosci. 27, 169-192. (doi:10.1146/ annurev.neuro.27.070203.144230)

Schumann, C. M., Hamstra, J., Goodlin-Jones, B. L., Lotspeich, L. J., Kwon, H., Buonocore, M. H., Lammers, C. R., Reiss, A. L. \& Amaral, D. G. 2004 The amygdala is enlarged in children but not adolescents with autism; the hippocampus is enlarged at all ages. F. Neurosci. 24, 6392-6401. (doi:10.1523/ineurosci. 1297-04.2004)

Schürmann, M., Hesse, M. D., Stephan, K. E., Saarela, M., Zilles, K., Hari, R. \& Fink, G. R. 2005 Yearning to yawn: the neural basis of contagious yawning. Neuroimage 24, 1260-1264. (doi:10.1016/j.neuroimage.2004. 10.022)

Zilbovicius, M., Meresse, I., Chabane, N., Brunelle, F., Samson, Y. \& Boddaert, N. 2006 Autism, the superior temporal sulcus and social perception. Trends Neurosci. 29, 359-366. (doi:10.1016/j.tins.2006.004) 